\title{
Synthesis and Properties of Porous Ti-20 wt.\% HA Nanocomposites
}

\author{
K. Niespodziana \\ (Submitted April 19, 2018; in revised form December 6, 2018; published online March 7, 2019)
}

\begin{abstract}
In the present study, porous titanium-20 wt.\% hydroxyapatite nanocomposites were produced by the combination of mechanical alloying and powder metallurgical process with the addition of titanium hydride particles as the blowing agent. The powder mixture of $\mathrm{Ti}, \mathrm{HA}$ and spacer particles were milled, pressed and heat-treated to decompose the hydride particles and to sinter into highly porous Ti-HA materials. The resulting microstructures were characterized using $x$-ray diffraction and scanning electron microscope with energy-dispersive spectrometry. The porosity, compressive strength and corrosion resistance of the porous nanocomposites were investigated. The results show that the compressive strength of porous Ti-HA can be tailored between 210 and 497 MPa by changing the content of blowing agent between 25 and $75 \%$. The increase in the weight ratio of titanium hydride (from 25 to $75 \%$ ) causes almost a twofold increase in the porosity and decreases the corrosion resistance (by almost two orders of magnitude). The present study has demonstrated that the porous Ti-HA nanocomposites are promising scaffold biomaterials for bone tissue engineering by virtue of their appropriate mechanical and corrosion properties and highly porous structure.
\end{abstract}

Keywords metallic matrix composites, porous materials, powder metallurgy

\section{Introduction}

There is a high demand for biomaterials to assist the replacement of diseased bones in the body. The best materials for bone replacement implants should have properties similar to the properties of the living bone. Till now, many studies on the use of metals, ceramics or polymers as artificial implant biomaterials have been done. However, both ceramics and polymeric materials have relatively low-strength properties which limit their use as bone replacement implants. On the other hand, mechanical properties of metallic materials are often too high compared to the properties of the bone. Among the basic metallic biomaterials (titanium and its alloys, stainless steel and cobalt-chromium alloys), titanium and some of its alloys possess the most favorable properties. Titanium is characterized by good mechanical properties, corrosion resistance and biocompatibility. However, major limitations of titanium are poor tribological properties, inadequate mechanical properties, lack of capability to induce bone tissue regeneration. For example, the significant difference between the Young's modulus of titanium $(110 \mathrm{GPa})$ and bone (2-20 GPa) may induce the formation of stress which results in tissue underload, a weakening of the tissue/implant connection, increasing bone porosity and consequently reducing the lifetime of the titanium implant (Ref 1-3). One of the effective ways to decrease the Young's modulus is to introduce pores in the dense structure of

K. Niespodziana, Poznan University of Technology, Institute of Materials Science and Engineering, M. Sklodowska-Curie 5, 60-965 Poznan, Poland. Contact e-mail: katarzyna.niespodziana@put.poznan.pl. titanium. For bone implant, biomaterial porous structure is crucial to ensure necessary space for cell ingrowth and vascularization (Ref 4, 5). Different researches indicate that in porous bone implants, the optimal pore size for attachment, differentiation, growth of osteoblasts and vascularization is in the range of $100-500 \mu \mathrm{m}$ (Ref 6-8). According to some authors (Ref 9-11), very important condition for the above features to be present is the presence of proper interconnections between pores. The interconnection sizes are critical in determining the quality of tissue ingrowth. Thus, high porosity enhances osteoconduction, but on the other hand too high value of this may lead to loss mechanical properties of biomaterial. As a part of osteoconduction, the ideal bone replacement material should be bioresorbable at sufficient degree for the proper formation of new bone. One of the methods that allow the change and further improvement in the interaction between porous titanium and natural tissues is to produce a composite containing ceramic phase-hydroxyapatite (HA). In this case, titanium provides mechanical properties, while HA assures biocompatibility. It is because hydroxyapatite has similar chemical and crystallographic structure to the apatite of living bone. Besides HA has porous nature and the ability to form strong chemical bonds with natural bone (Ref 12, 13). Moreover, HA has unique biological property - during the time it is partially resorbed and replaced by new natural bone (Ref 14). Our earlier works (Ref 15-17) showed that titanium-ceramic nanocomposites, produced by mechanical alloying and powder metallurgical method, possess greater Vickers hardness, lower Young's modulus, better corrosion resistant and good biocompatibility compared to microcrystalline titanium. Therefore, in this study, we demonstrate the possibility of using mechanical alloying and powder metallurgical process for the production of porous Ti-HA nanocomposites. In addition, titanium hydride powder was used as the blowing agent for the formation of porous materials. The porous structures and some properties of the fabricated samples were examined, and the obtained results are discussed. 


\section{Materials and Methods}

The commercial titanium (Alfa Aesar, purity $>99 \%$, powder size $<45 \mu \mathrm{m}$ ) and hydroxyapatite (Sigma-Aldrich, powder size $<50 \mu \mathrm{m}$ ) were used as starting materials. Titanium hydride (Alfa Aesar, purity $>99 \%$, powder size $<45$ $\mu \mathrm{m})$ was used as blowing agent. Figure 1 shows SEM micrographs of the starting titanium, hydroxyapatite and titanium hydride powders.

The Ti-20 wt.\% HA nanocomposite materials were synthesized by mechanical alloying and powder metallurgical process. Mechanical alloying was performed under argon atmosphere using a SPEX 8000 Mixer Mill. The vial was loaded and unloaded in Labmaster 130 glove box in high-purity argon atmosphere. The starting mixture of $\mathrm{Ti}$ and $\mathrm{HA}$ powders was ball-milled with hard steel ball for $48 \mathrm{~h}$. Titanium hydride (blowing agent) was added at the end of the milling. Ti$\mathrm{HA}+\mathrm{TiH}_{2}$ composites were prepared with various amounts of $\mathrm{TiH}_{2}$ powders. The ratio of Ti-HA to $\mathrm{TiH}_{2}$ was 4:1, 4:2, 4:3, respectively. Ti-HA and $\mathrm{TiH}_{2}$ powders were thoroughly mixed in an agate mortar for $1 \mathrm{~min}$. After obtaining a homogeneous mixture, powders were uniaxially pressed at a pressure of 210 or $415 \mathrm{MPa}$. After that, green compacts were heat-treated in two steps:

- heated up to $700{ }^{\circ} \mathrm{C}$ and kept at this temperature for $2 \mathrm{~h}$ (vacuum) to decompose hydride into hydrogen (introduces porosity into the material) and titanium (participates in further synthesis),

- heated up to $1150{ }^{\circ} \mathrm{C}$ and kept at this temperature for $2 \mathrm{~h}$ (argon) for consolidation of Ti-HA powders.

Three samples were made for each experimental condition. Further, the samples were determined according to the indications shown in Table 1.

The titanium, hydroxyapatite and titanium hydride powders were examined, at the various stages during milling, prior to sintering and after sintering, by means of $\mathrm{x}$-ray diffraction (XRD), with $\mathrm{Cu} \mathrm{K}_{\alpha 1}$ radiation, and high-resolution transmission electron microscopy (TEM). The TEM images and selected area electron diffraction (SAED) patterns were recorded with a Philips CM 20 Super Twin microscope, which provides a $0.24 \mathrm{~nm}$ resolution at acceleration voltage of $200 \mathrm{kV}$. Typical crystallite sizes were estimated from the halfwidth of lines using the Scherrer equation. The decomposition behavior of the $\mathrm{TiH}_{2}$ was examined using DSC Q20 calori- metric measurement. Heating range was from 20 to $720{ }^{\circ} \mathrm{C}$ in a nitrogen atmosphere. Scanning electron microscope (SEM) with energy-dispersive $\mathrm{x}$-ray spectrometer (EDS) was used to study the microstructure, the pore morphology and the chemical composition of the prepared nanocomposites. Powder morphology was investigated by Quesant Q-250 atomic force microscopy (AFM). The density was determined by Archimedes method using distilled water. The porosity was measured using image analyzer and also was estimated with the following equation:

$P=\left[\left(\rho_{t}-\rho\right) / \rho_{t}\right] \cdot 100 \%$

where $\rho_{\mathrm{t}}$ is a theoretical density and $\rho$ is a density.

Image analysis was also used to assess the size of macropores. Additionally, the properties related to the mesoporosity were measured using Micrometrics ASAP 2020 Analyzer. Surface area, pore volume and pore size analysis of the sintered composites were determined by BET (BrunauerEmmett-Teller) method. The compressive strength tests were carried out on specimens with a size of $10 \mathrm{~mm}$ in diameter and $5 \mathrm{~mm}$ in height using a Zwick Z100 testing machine with a crosshead speed of $1 \mathrm{~mm} / \mathrm{min}$ at room temperature. The corrosion resistance was measured using potentiodynamic corrosion test which was carried out using a Solartron potentiostat, Model 1285. Two graphite rods were used as the counter electrodes, and a platinum electrode was used as the reference electrode. Corrosion test was performed in Ringer solution ( $\mathrm{pH}$ 7.0) and Hanks' balanced salt solution-HBSS ( $\mathrm{pH}$ 7.14-7.46) - with the composition presented in Table 2. The electrolyte was maintained at a temperature of $37^{\circ} \mathrm{C}$ throughout all experiments. The surface area exposed to the electrolyte was $0.75 \mathrm{~cm}^{2}$. Corrosion potentials $\left(E_{\mathrm{c}}\right)$ and corrosion current densities $\left(i_{\mathrm{c}}\right)$ were determined by Tafel extrapolation methods.

Table 1 List of indications of sintered porous nanocomposites

\begin{tabular}{lcc}
\hline & \multicolumn{2}{c}{ Compaction pressure, MPa } \\
\cline { 2 - 3 } Specimen & $\mathbf{2 1 0}$ & $\mathbf{4 1 5}$ \\
\hline Ti-20 wt.\% HA + 25 wt.\% $\mathrm{TiH}_{2}$ & $\mathrm{~A} 1$ & $\mathrm{~A} 2$ \\
Ti-20 wt.\% HA + 50 wt.\% $\mathrm{TiH}_{2}$ & $\mathrm{~B} 1$ & $\mathrm{~B} 2$ \\
Ti-20 wt.\% HA +75 wt.\% $\mathrm{TiH}_{2}$ & $\mathrm{C} 1$ & $\mathrm{C} 2$ \\
\hline
\end{tabular}
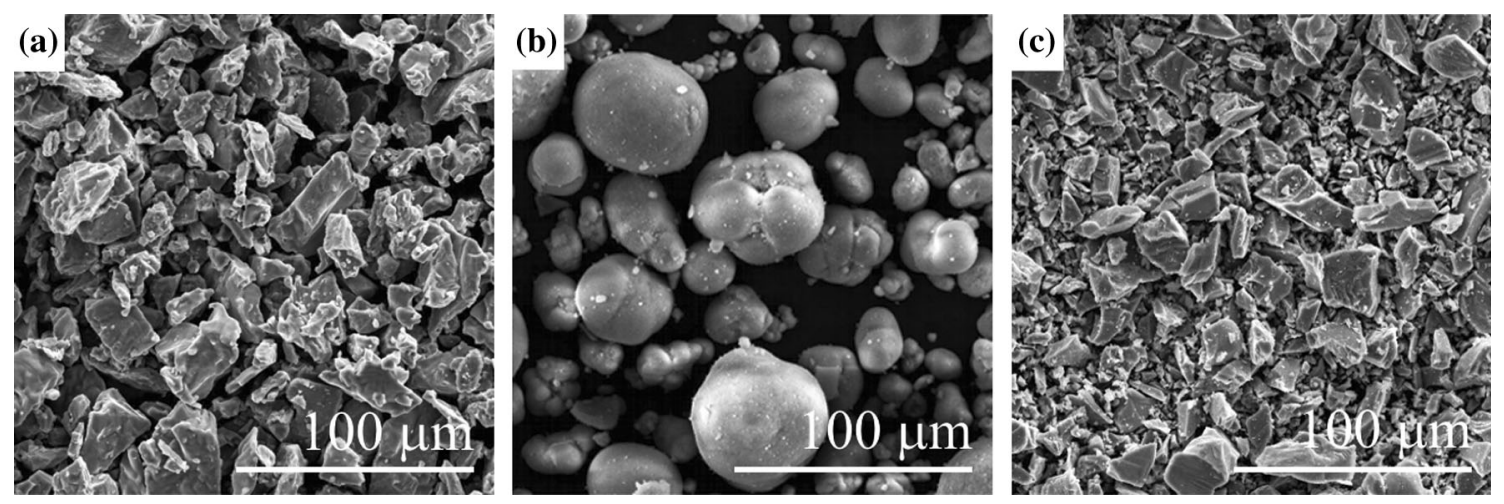

Fig. 1 SEM morphologies of raw (a) titanium, (b) hydroxyapatite and (c) titanium hydride powders 
Table 2 Composition (g/L) of Ringer solution and Hanks' balanced salt solution (HBSS)

\begin{tabular}{lllllllll}
\hline & $\mathbf{N a C l}$ & $\mathbf{K C l}$ & $\mathbf{C a C l}_{\mathbf{2}}$ & $\mathbf{N a H C O}_{\mathbf{3}}$ & $\mathbf{K H}_{\mathbf{2}} \mathbf{P O}_{\mathbf{4}}$ & $\mathbf{N a H}_{\mathbf{2}} \mathbf{P O}_{\mathbf{4}} \cdot 7 \mathrm{H}_{\mathbf{2}} \mathbf{O}$ & $\mathbf{G l u c o s e}_{\mathbf{6}} \mathbf{C}_{\mathbf{1 2}} \mathbf{O}_{\mathbf{6}}$ \\
\hline Ringer solution & 9.0 & 0.42 & 0.48 & 0.2 & $\ldots$ & $\ldots$ & $\ldots$ \\
HBSS & 8.0 & 0.4 & $\ldots$ & 0.35 & 0.06 & 0.09 & 1.0 \\
\hline
\end{tabular}

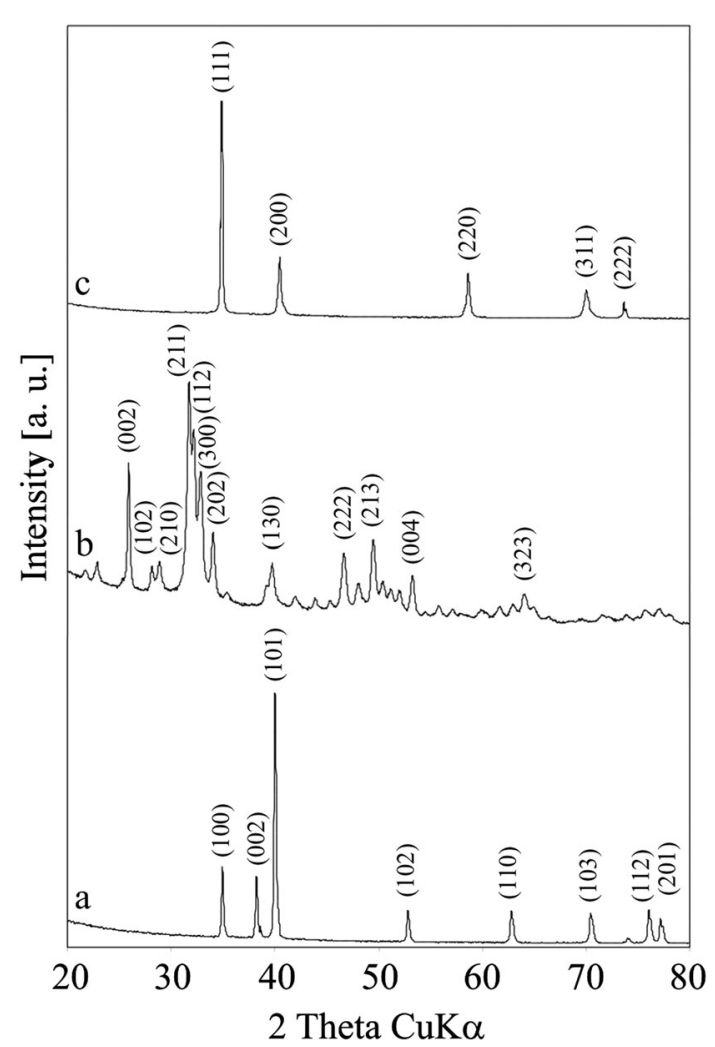

Fig. 2 XRD spectra of raw (a) titanium, (b) hydroxyapatite and (c) titanium hydride powders

\section{Results}

The possibility of synthesis porous Ti-HA nanocomposites using mechanical alloying and powder metallurgical process is presented first. The influence of processing conditions and different amounts of pore-forming agent upon the Ti-HA properties is then discussed.

X-ray diffraction was employed to study the effect of mechanical alloying and heat treatment on Ti-based composites. Figure 2 shows the XRD patterns of the starting titanium and hydroxyapatite powders and XRD pattern of blowing agent - titanium hydride. All raw materials possess a crystalline structure: Ti and HA hexagonal and $\mathrm{TiH}_{2}$ cubic. Figure 3 shows the XRD patterns of the titanium and hydroxyapatite powders at different stages of mechanical alloying process. During MA process, the powder particles of Ti and HA are periodically trapped between colliding balls and are plastically deformed what occurs by the generation of a wide number of dislocations as well as other lattice defects. The originally sharp diffraction lines of Ti and HA gradually become broader and their intensities decrease with milling time (Fig. 3a-c). The peak broadening represents a reduction in the crystallite size

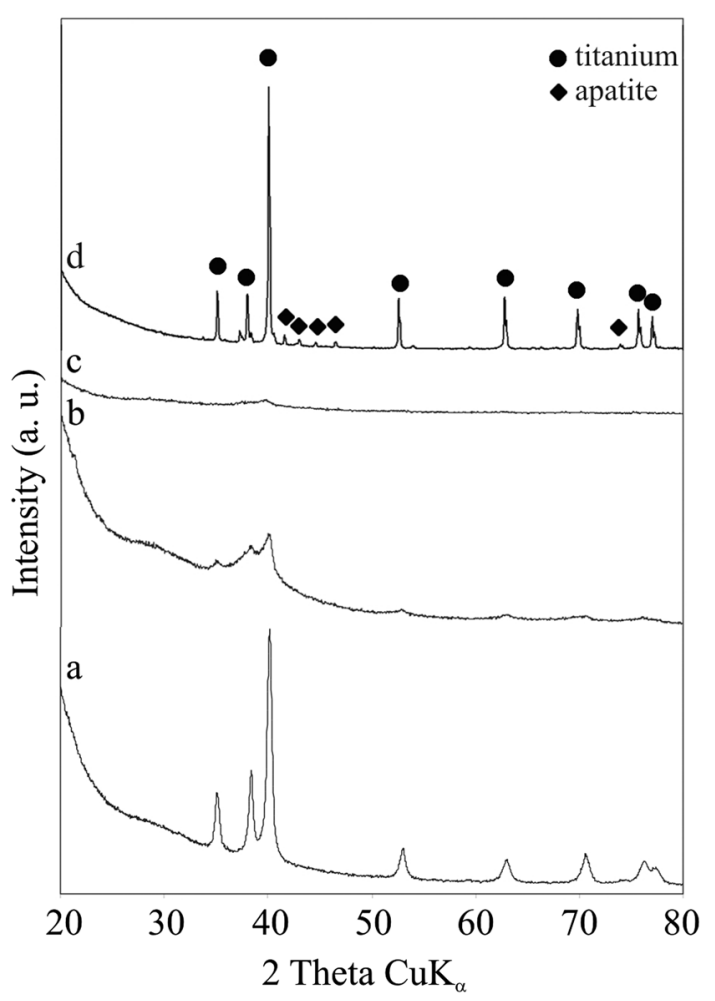

Fig. 3 XRD spectra of $\mathrm{Ti}$ and HA (20 wt.\%) powders mechanically alloyed for different times: (a) $5 \mathrm{~h}$, (b) $20 \mathrm{~h}$, (c) $48 \mathrm{~h}$, (d) after heat treatment in two steps: at $700{ }^{\circ} \mathrm{C}$ for $2 \mathrm{~h}$ and at $1150{ }^{\circ} \mathrm{C}$ for $2 \mathrm{~h}$

and an increase in the internal strain in the MA materials. SEM micrographs of milled materials confirm that mechanical alloying process causes fracture of the elementary particles (Fig. 4). It can be seen that after $20 \mathrm{~h}$ of milling, the powder shows an inhomogeneous size distribution (Fig. 4c). With the increase in milling time, the size of the mixed powders decreases gradually and its morphology is more homogeneous (Fig. 4d).

After mechanical alloying process, the powder was agglomerated and the agglomerate size was below $100 \mathrm{~nm}$ as shown by the AFM results in Fig. 5. In turn, according to the Scherrer method of XRD profile, the mean crystallite size of these nanocomposites was determined to be $5 \mathrm{~nm}$. After $48 \mathrm{~h}$ of mechanical alloying process, the mixtures of the microcrystalline pure elemental powders of titanium and hydroxyapatite have transformed almost into an amorphous phase (Fig. 3c) which was confirmed by TEM research (Fig. 6). The SAED pattern contains broad rings at position expected for Ti with hexagonal structure (the ring position matches (101) Ti lattice reflection). The TEM results reveal that, apart from the dominant amorphous phase, the milled powder also contains a small amount of grains with nanoparticles of titanium (not 

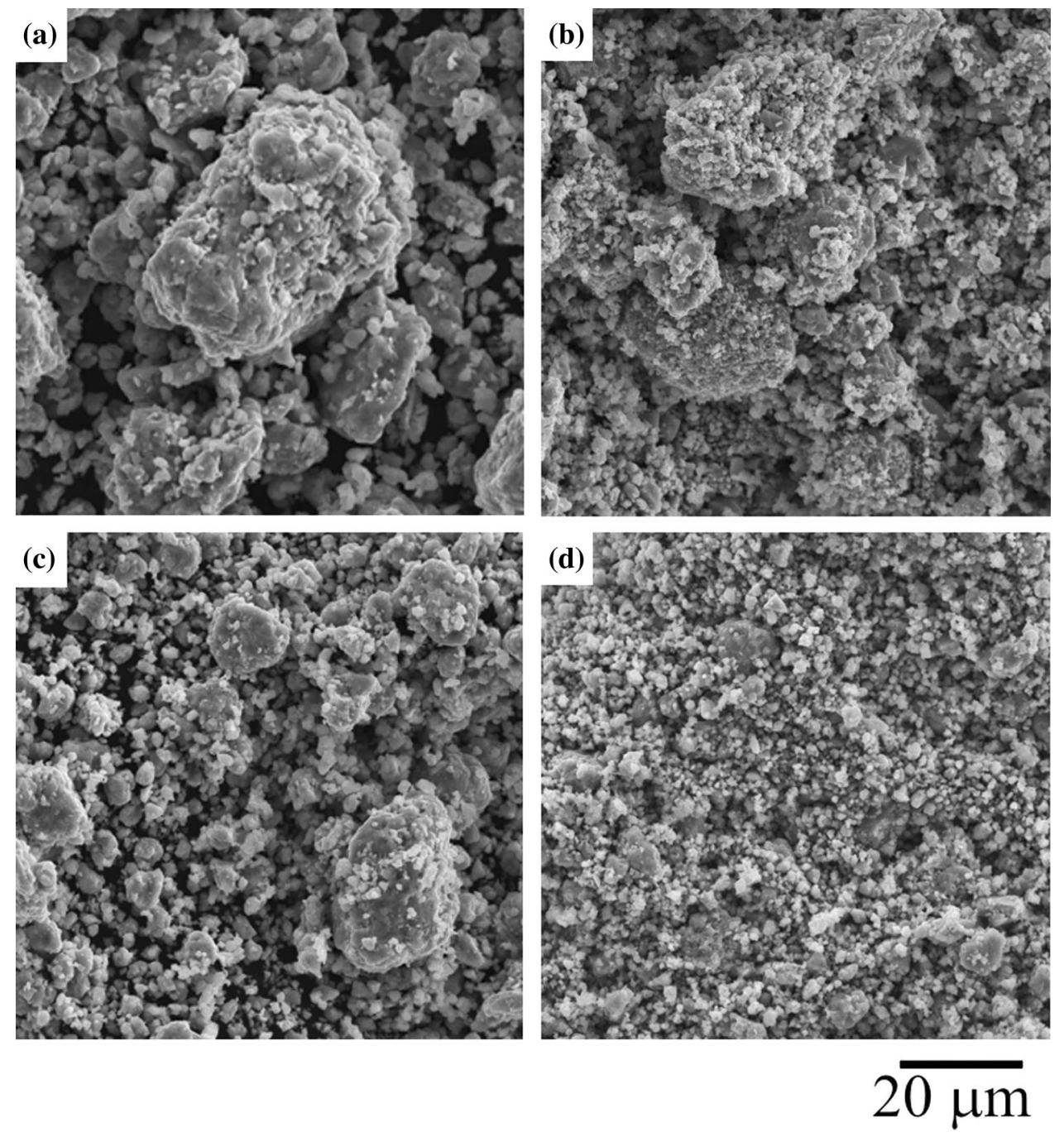

Fig. 4 SEM morphologies of Ti-20 wt.\% HA powders mechanically alloyed for different times: (a) 5 h, (b) 10 h (c) 20 h, (d) 48 h (scale bar applies to all images)

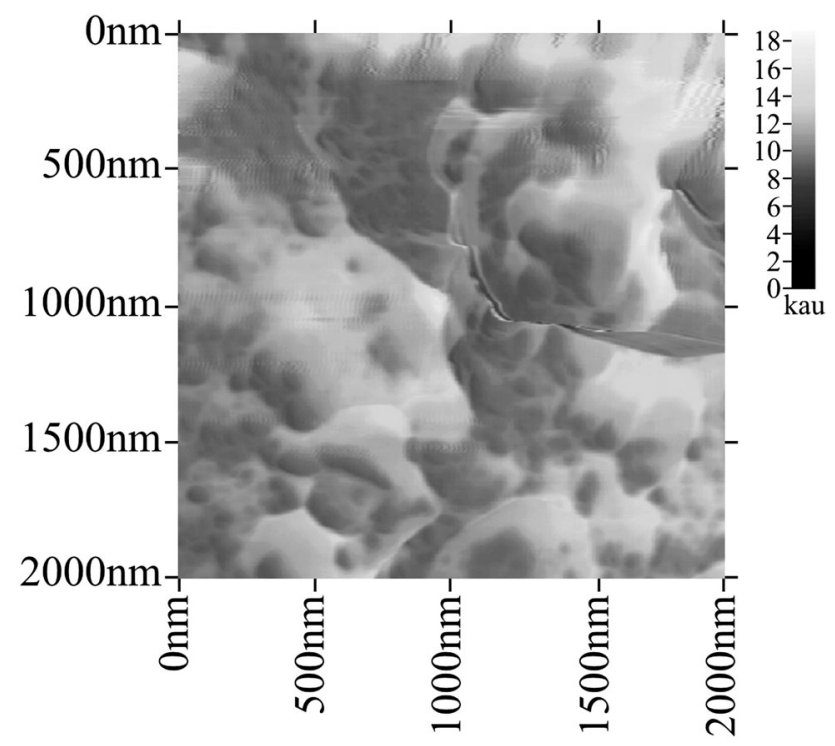

Fig. 5 AFM analysis of Ti- 20 wt.\% HA powders after $48 \mathrm{~h}$ of mechanical alloying

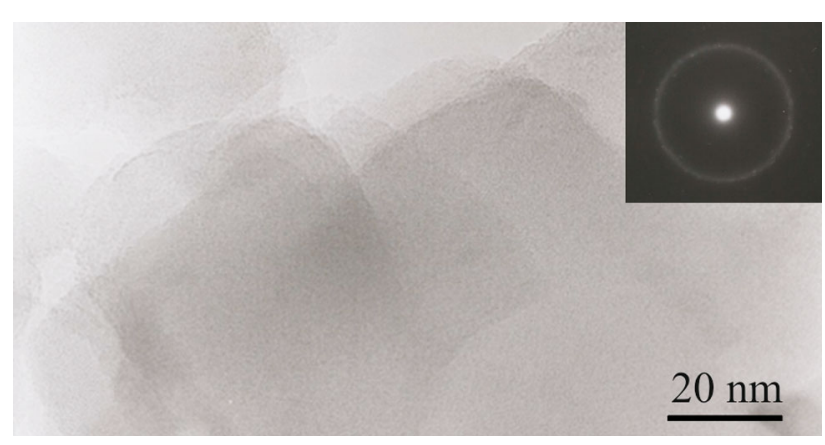

Fig. 6 TEM micrographs of the milled Ti-20 wt.\% HA sample for $48 \mathrm{~h}$-typical amorphous parts with corresponding SAED patterns (top right corner)

shown). The lack of any sharp reflections in the XRD pattern (Fig. 3c) suggests that the amount of the nanocrystalline phase is very low.

The formation of the bulk porous Ti-HA nanocomposites was achieved by sintering of the amorphous materials with the addition of suitable blowing agent. Thermal analysis of $\mathrm{TiH}_{2}$ 
powders was carried out to characterize their decomposition temperature and to determine the burning temperature of this component. The DSC result of $\mathrm{TiH}_{2}$ powders is shown in Fig. 7. The results showed that the decomposition of $\mathrm{TiH}_{2}$ was a two-step process. The first transformation temperature is located at $520{ }^{\circ} \mathrm{C}$, and the second is around $615{ }^{\circ} \mathrm{C}$. These two transformation temperatures are explained by the two possible non-equivalent positions of hydrogen atoms in titanium: one with tetrahedral and the other with octahedral symmetry (Ref 18).

Before heat treatment, the samples consisted of amorphous Ti-HA powders and crystalline $\mathrm{TiH}_{2}$ powders. After heat treatment, the samples showed only peaks associated with the crystalline $\alpha$-Ti phase and apatite phase without any secondary phases (Fig. 3d), indicating the complete decomposition of the $\mathrm{TiH}_{2}$ powders. After heat treatment, the mean crystallite size of the porous nanocomposites estimated from XRD experiment were about $20-45 \mathrm{~nm}$.

Examples of scanning electron micrograph of the surface of sintered porous nanocomposite (sample C1) with EDS spectra are shown in Fig. 8.

The extreme heating conditions $\left(1150^{\circ} \mathrm{C}\right)$ cause the decomposition of HA phase and the formation of apatite with different $\mathrm{Ca} / \mathrm{P}$ ratios. Other sintered porous nanocomposites have similar phase constitution.

The different titanium hydride content before heat treatment in Ti-HA nanocomposites leads to a change in the properties. The tested properties of porous Ti-HA nanocomposite materials are listed in Table 3. In order to make comparison, the characteristic of non-porous Ti-HA nanocomposite is also listed in Table 3.

It is obvious that lower density is obtained for the nanocomposites pressed at a lower pressure $(210 \mathrm{MPa})$. With an increase in the applied compaction pressure, the porosity tends to decrease. For all samples, the porosity determined from image analysis has a higher value than that determined from Eq 1. The difference in porosity is in the range from about 1 to $15 \%$.

Our earlier work shown that the use of mechanical alloying and powder metallurgical process leads to the formation of bulk Ti-HA nanocomposites characterized by a porosity of about $10 \%$ (Ref 15). The samples prepared with the addition of $\mathrm{TiH}_{2}$ show from two to five times higher porosity than those without $\mathrm{TiH}_{2}$. Despite the significant difference in the amount of blowing agent in Ti-HA nanocomposites, changes in porosity are not so significant and amount of about $15 \% *$ or $30 \% * *$ (depending on the measurement method). With the increase in

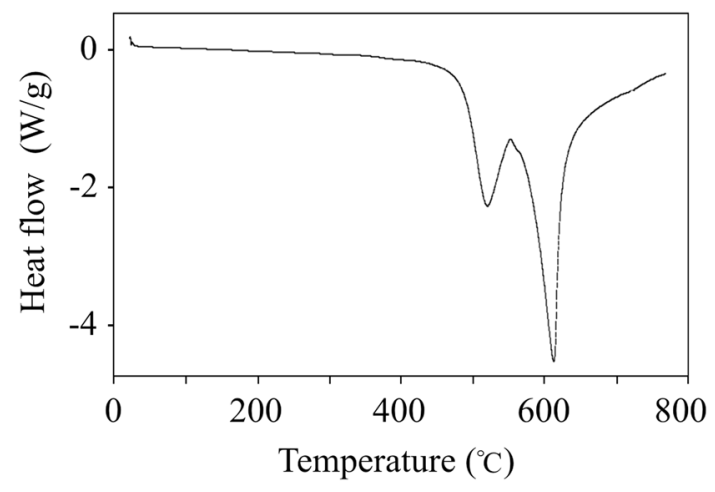

Fig. 7 DSC of $\mathrm{TiH}_{2}$ powder the addition of $\mathrm{TiH}_{2}$, the sintered samples have greater number of large pores. Image analysis draws the conclusion that sintered Ti-HA nanocomposites are characterized by a heterogeneous distribution of porosity (Fig. 9). The homogeneity of pore distribution increases with the addition of $\mathrm{TiH}_{2}$. Besides, in porous Ti-HA nanocomposites, participation of a large pore size increases with the rise of $\mathrm{TiH}_{2}$ content. On the polished surface can be observed two types of areas characterized by the presence of different numbers and sizes of pores. The first area occurs a large number of porosity of a large pore sizes (80$100 \mu \mathrm{m})$, the second area occurs a large number of very small pore sizes $(<10 \mu \mathrm{m})$ which is particularly evident at the higher magnification (Fig. 10). Additionally, in Fig. 11, the exemplary histogram of the pore size distribution has been shown. All the samples prepared with the addition of $\mathrm{TiH}_{2}$ show highly porous and developed structure. This is especially visible for the samples containing 50 and $75 \%$ blowing agent. For these samples, the largest part of the porosity was open and interconnected. The samples containing $25 \%$ of $\mathrm{TiH}_{2}$ possess a smaller pore size, and pore interconnectivity is not visible, so these structures are not interesting for use as scaffolds. Thus, the contribution of the blowing agent is very important. The low proportion of the blowing agent results in the formation of insufficiently porous structures. On the other hand, too much blowing agent contributes to the formation of excessively porous and relatively brittle materials.

Several studies have shown that, apart from macroporosity ( $>50 \mathrm{~nm}$ ), also mesoporosity $(2-50 \mathrm{~nm})$ and microporosity $(<2 \mathrm{~nm})$ are essential for biomaterial's osteoinductivity (Ref 19-21). For this reason, some properties related to the mesoporosity were measured. The exemplary results of the BET analysis are shown in Fig. 12 and listed in Table 4. The average adsorption pore width was estimated to be about 7 $8 \mathrm{~nm}$. The results show that the fraction of mesoporosity in the structure of the investigated materials is negligible. Thus, in this case, the mesoporosity has no significant effect on the properties of the obtained samples.

Obtaining a porous structure also had no effect on the reduction in the strength properties of sintered nanocomposites. The mechanical properties of sintered porous nanocomposites were studied by the compressive strength tests (Table 3 ).

The stress versus strain response of the porous nanocomposites is shown in Fig. 13. Most of the sintered samples showed similar stress versus strain responses. Only in the case of the samples containing initially $25 \%$ of $\mathrm{TiH}_{2}$, after crossing the maximum compressive stress, there was observed more rapid destruction of the material. On the other hand, these porous nanocomposites exhibited a compressive strength of 365 and $497 \mathrm{MPa}$ (depending on the compaction pressure), which is the highest values in comparison with other fabricated porous nanocomposites. As the initial $\mathrm{TiH}_{2}$ content increased from 25 to $75 \%$, regardless of the value of compression pressure, the compressive strength was decreased by more than twice. The use of a higher compaction pressure, for the samples with the same amount of titanium hydride, results in a greater resistance to compression. It is connected with a greater number of pores and higher porosity in materials with less the value of the compaction pressure. The compressive strengths of porous Ti-HA $\left(+25 \% \mathrm{TiH}_{2}\right)$ nanocomposites pressed at a pressure of 210 and $415 \mathrm{MPa}$ were 365 and $497 \mathrm{MPa}$ (reduction of $132 \mathrm{MPa}$ ), while at the same compaction pressure the compressive strengths for porous $\mathrm{Ti}-\mathrm{HA}\left(+50 \% \mathrm{TiH}_{2}\right)$ nanocomposites were 250 and $329 \mathrm{MPa}$ (reduction of $79 \mathrm{MPa}$ ), 


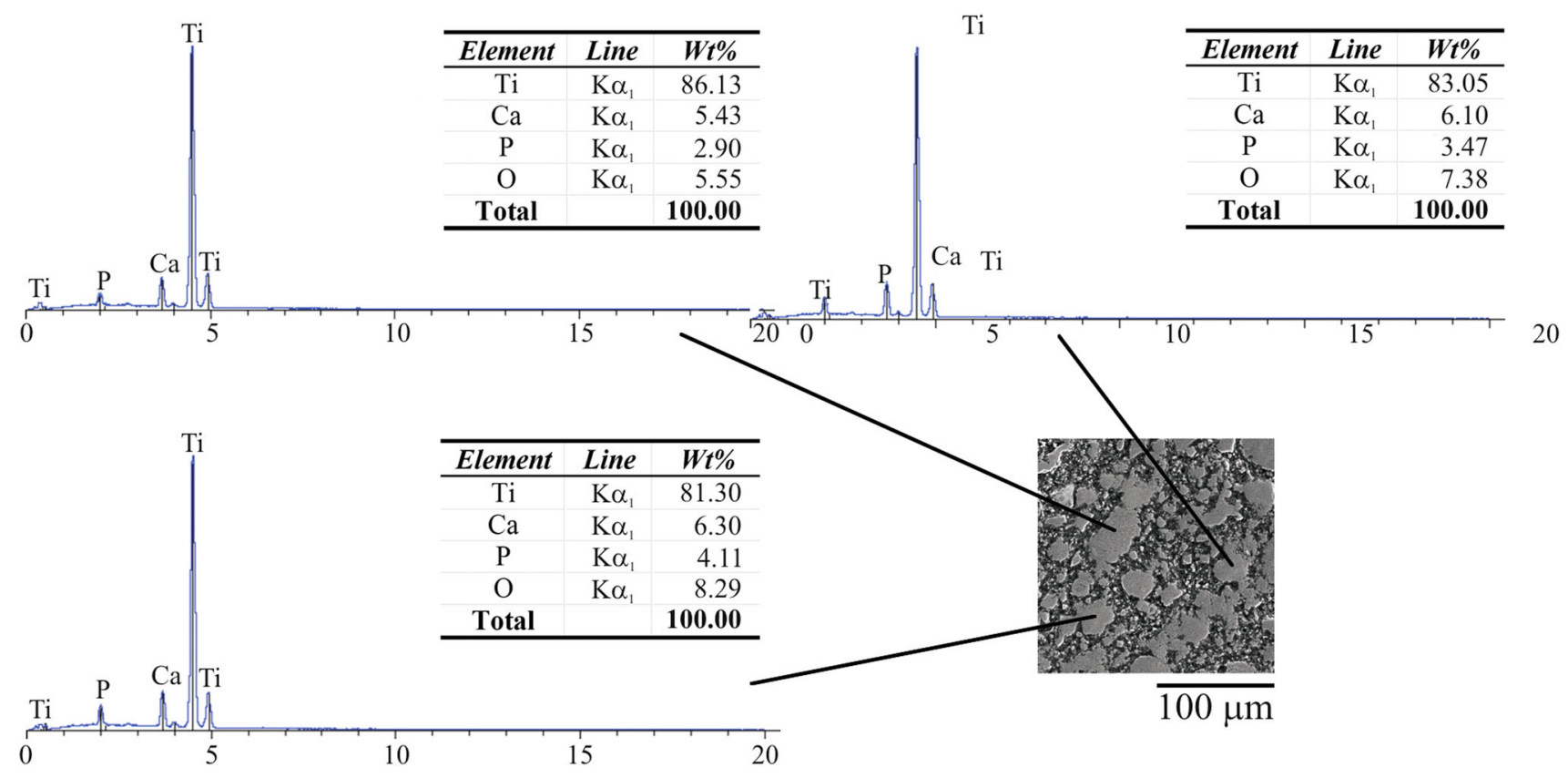

Fig. 8 EDS spectra of surface of Ti-20 wt.\% HA nanocomposite mechanically alloyed for $48 \mathrm{~h}$ and heat-treated in two steps: at $700{ }^{\circ} \mathrm{C}$ for $2 \mathrm{~h}$ and at $1150{ }^{\circ} \mathrm{C}$ for $2 \mathrm{~h}$

Table 3 Density $(\rho)$, porosity $(P)$, compressive strength $\left(\sigma_{c}\right)$ of porous and non-porous Ti-HA nanocomposites

\begin{tabular}{lcccc}
\hline Materials & $\boldsymbol{\rho}, \mathbf{g} / \mathbf{c m}^{\mathbf{3}}$ & $\mathbf{P}^{*}, \boldsymbol{\%}$ & $\mathbf{P}^{* *}, \boldsymbol{\%}$ & $\boldsymbol{\sigma}_{\mathbf{c}}, \mathbf{M P a}$ \\
\hline A1 & 3.38 & 21.2 & 22.1 & 365 \\
A2 & 3.62 & 15.6 & 16.5 & 497 \\
B1 & 3.07 & 28.3 & 35.3 & 250 \\
B2 & 3.34 & 22.0 & 25.3 & 329 \\
C1 & 2.99 & 30.2 & 45.5 & $\ldots$ \\
C2 & 3.09 & 27.9 & 36.1 & 210 \\
Ti-20 wt.\% HA(a) & 3.91 & 9.1 & $\ldots$ & 295
\end{tabular}

*Calculated using formula (1)

**Calculated on the basis of image analysis

(a) Compaction pressure $415 \mathrm{MPa}$, heat treatment $1150{ }^{\circ} \mathrm{C} / 2 \mathrm{~h}$

respectively. It is worth noting that porous nanostructured composites contained 25 and $50 \%$ of $\mathrm{TiH}_{2}$ posses higher compressive strengths compared to non-porous nanocomposite pressed at the same pressure.

Table 5 summarizes mean values of corrosion current densities $\left(i_{\mathrm{C}}\right)$ and corrosion potentials $\left(E_{\mathrm{C}}\right)$ determined from the potentiodynamic polarization curves by Tafel extrapolation method for each porous Ti-HA nanocomposite. Further, in Fig. 14 and 15 are compared polarization curves of porous TiHA (+ 25\% and 50\% $\mathrm{TiH}_{2}$, compaction pressure $\left.415 \mathrm{MPa}\right)$ obtained at different corrosion solutions. Examination of the curves shows that there are no major differences between the general types of electrochemical behavior of porous Ti-HA nanocomposites in the two solutions. According to the data shown in Table 5, the values of corrosion current densities obtained in Ringer solution are smaller about one order of magnitude than those found in Hanks' balanced salt solution. Farther, regardless of the type of the electrolyte, at the same weight fraction of $\mathrm{TiH}_{2}$, the values of corrosion potentials increase with decreasing compaction pressure. Furthermore, the increase in the content of $\mathrm{TiH}_{2}$ (increase in porosity) also affected the decrease in corrosion resistance. All tested porous Ti-HA nanocomposites shown a negative value of the corrosion potential in various test solutions. Although there appeared to be no correlation between amount of $\mathrm{TiH}_{2}$ and corrosion potential, the data in Table 5 show that the increase in compaction pressure at the same weight fraction of $\mathrm{TiH}_{2}$ did cause the corrosion potential to shift in the less negative direction. (The exceptions are samples B1 and B2 measured in Ringer solution.) However, the trend of decreasing corrosion potential with increasing compaction is more noticeable for samples tested in Ringer solution.

\section{Discussion}

Bulk titanium-hydroxyapatite composites (Ref 22) and especially porous titanium-ceramic composites and titanium alloys have recently attracted extensive interests for their potential use as biomedical materials. Previously several methods have been employed to fabricate the porous Ti alloys and Ti-ceramic composites. The most common technique is the preparation of porous materials by powder metallurgy process with different spacer materials (Ref 23-25). Another potential method for creating porous structure is rapid prototyping (Ref 26, 27).

One of the stages of powder metallurgy process is the milling process. Replacing ball mills by high-energy ball mills can produce nanoparticles (and further nanomaterials) which have better properties than microcrystalline materials. During the mechanical alloying process, which takes place in the highenergy ball mills, the powder particles are repeatedly flattened, 

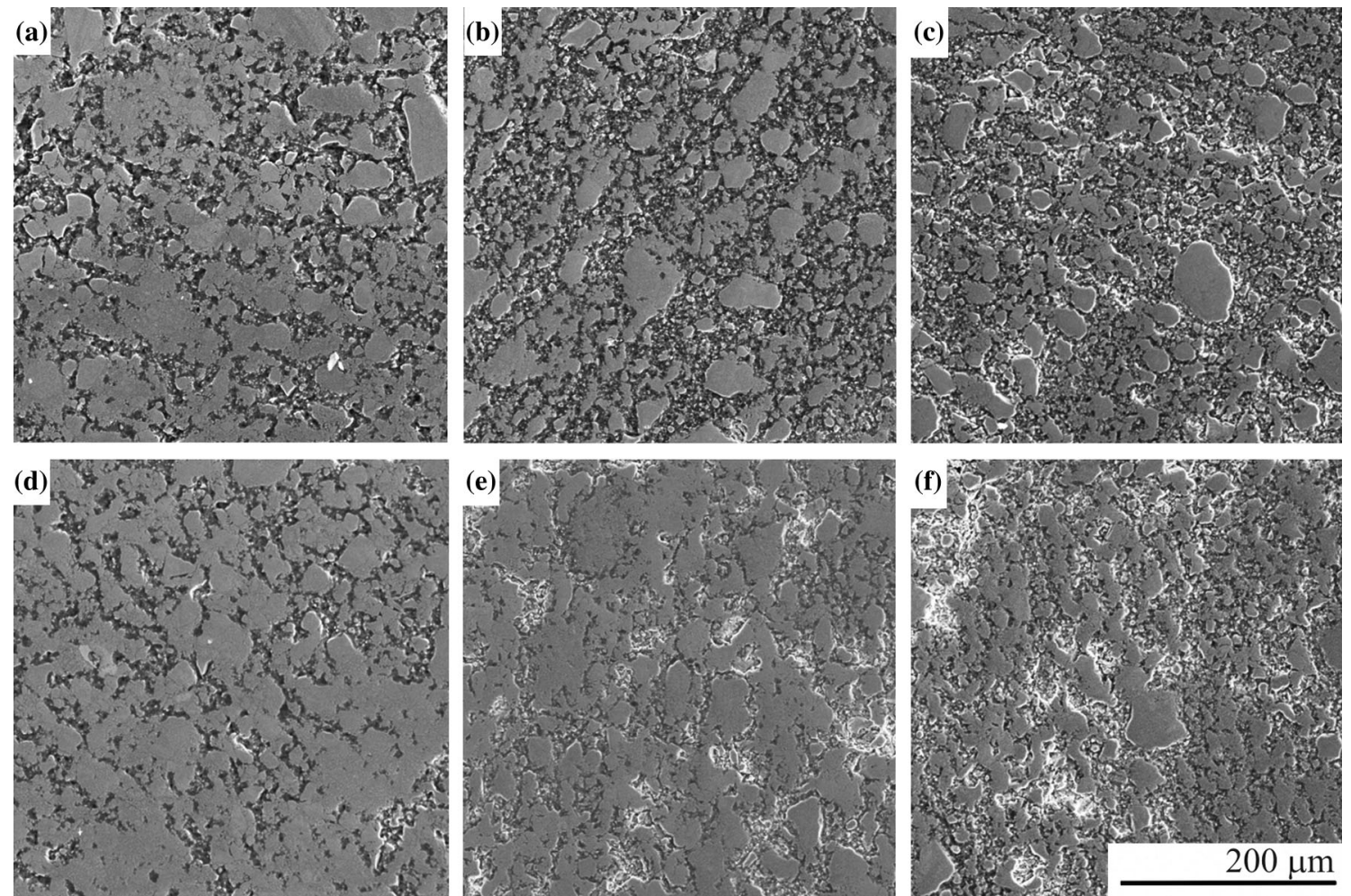

Fig. 9 SEM micrographs of polished surface of sintered porous Ti-HA nanocomposites with the addition of $\mathrm{TiH}_{2}$ : (a) 25\%, compaction pressure $210 \mathrm{MPa}$, (b) $50 \%$, compaction pressure $210 \mathrm{MPa}$, (c) $75 \%$, compaction pressure $210 \mathrm{MPa}$, (d) $25 \%$, compaction pressure $415 \mathrm{MPa}$, (e) $50 \%$, compaction pressure $415 \mathrm{MPa}$, (f) $75 \%$, compaction pressure $415 \mathrm{MPa}$ (scale bar applies to all images)
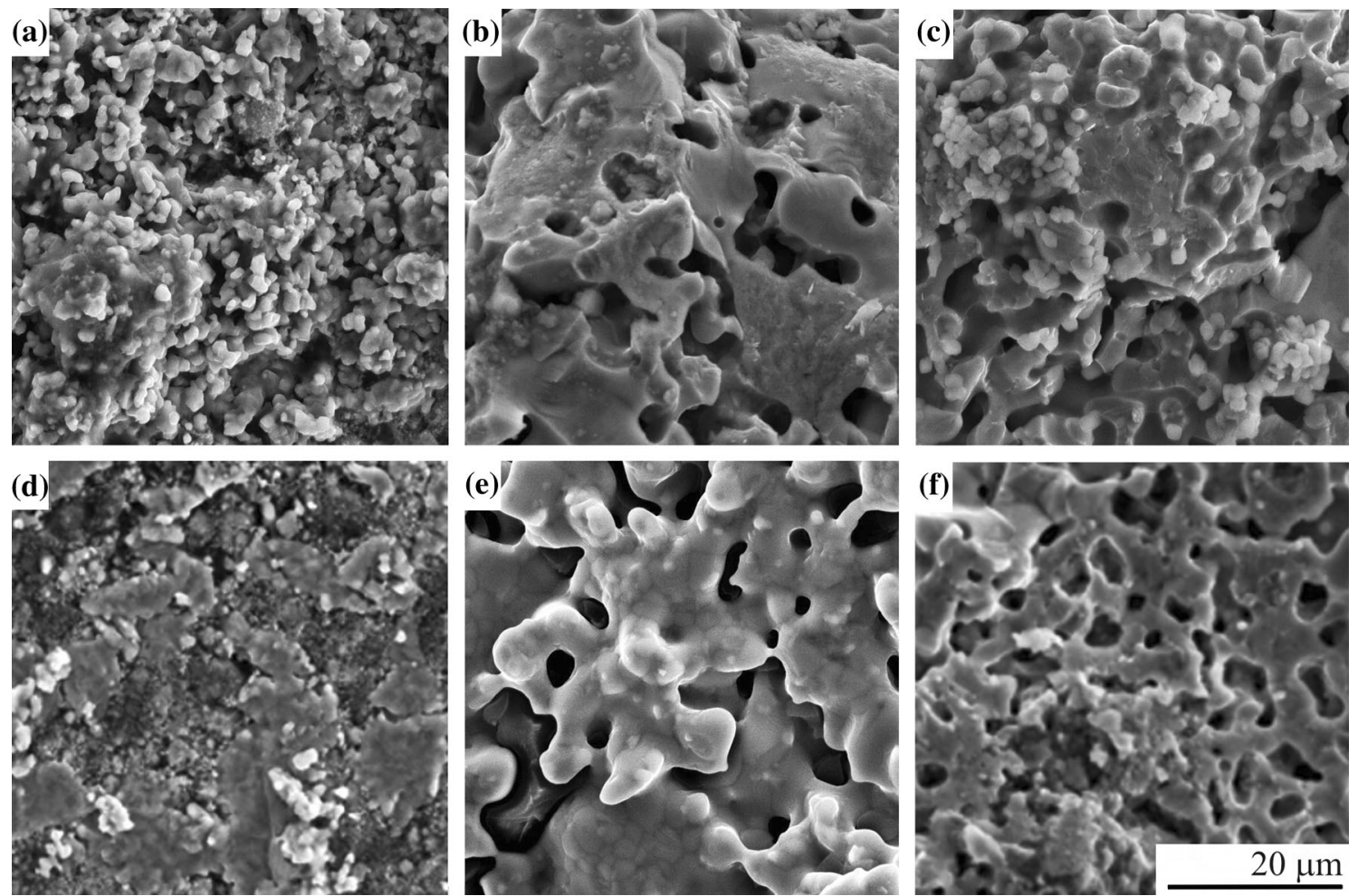

Fig. 10 SEM micrographs of the porous Ti-HA nanocomposites produced with various $\mathrm{TiH}_{2}$ contents: (a) $25 \%$, compaction pressure $210 \mathrm{MPa}$, (b) $50 \%$, compaction pressure $210 \mathrm{MPa}$, (c) $75 \%$, compaction pressure $210 \mathrm{MPa}$, (d) $25 \%$, compaction pressure $415 \mathrm{MPa}$, (e) $50 \%$, compaction pressure $415 \mathrm{MPa}$, (f) $75 \%$, compaction pressure $415 \mathrm{MPa}$ (scale bar applies to all images) 


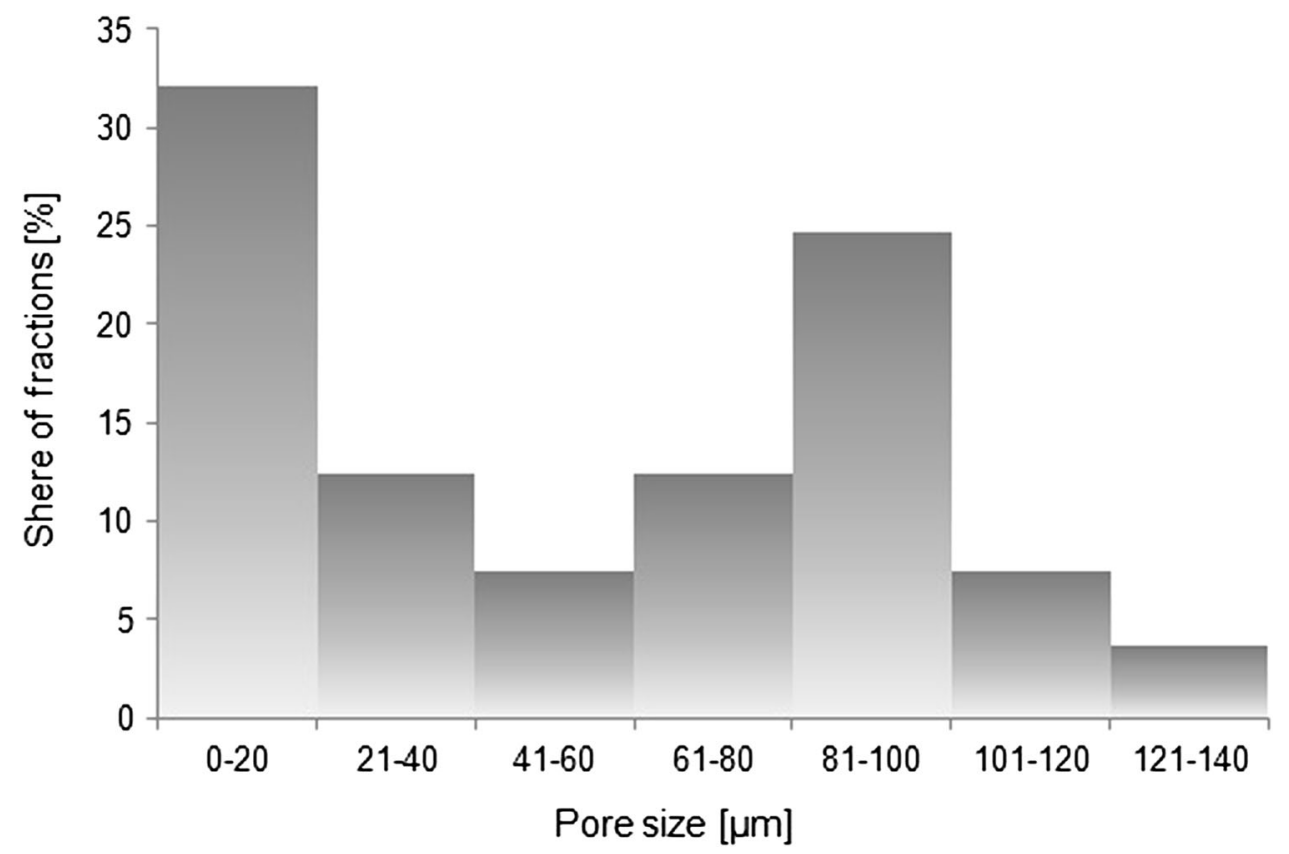

Fig. 11 Histogram of pore size distribution in a sample containing $50 \% \mathrm{TiH}_{2}$ and compressed at $210 \mathrm{MPa}$

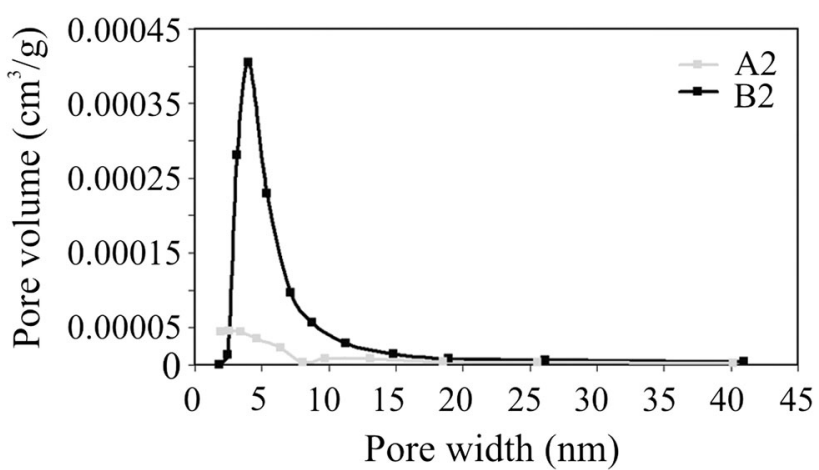

Fig. 12 Desorption cumulative pore volume of the porous Ti20 wt.\% HA nanocomposites with various $\mathrm{TiH}_{2}$ contents (A2-25\%, B2- $50 \%$, compaction pressure $415 \mathrm{MPa}$ )

Table 4 BET porosity parameters for the sintered porous Ti-HA nanocomposites

\begin{tabular}{lccc}
\hline Materials & $\boldsymbol{S}_{\mathbf{B E T}}, \mathbf{~ m}^{\mathbf{2}} / \mathbf{g}$ & $\boldsymbol{V}_{\mathbf{T}}, \mathbf{c m}^{\mathbf{3}} / \mathbf{g}$ & $\boldsymbol{d}_{\mathbf{A}}, \mathbf{n m}$ \\
\hline A2 & 0.23 & 0.0004 & 7.29 \\
B2 & 0.75 & 0.0014 & 7.84
\end{tabular}

$S_{\mathrm{BET}}, V_{\mathrm{T}}, d_{\mathrm{A}}$; BET surface area, total volume of pores, average pore size

cold-welded, fractured and rewelded, resulting in high deformation of particles and large dislocation density. As a result of MA, a variety of equilibrium and non-equilibrium phases with a nanometer size subgrains can be obtained (Ref 28). In this work, mechanical alloying of titanium and hydroxyapatite powders resulted in the formation of amorphous phase. Next, due to the addition of blowing agent and their thermal treatment, nanostructured Ti-20 wt.\% HA scaffolds were made.
The high deformation during the MA leads to an increase in the interfacial area, and the sizes of the elementary component area decrease from millimeter to nanometer lengths. The reduction in the crystallite size was confirmed by broadening of the diffraction peaks. XRD results showed that the addition of hydroxyapatite to titanium caused the increase in lattice constants of $\mathrm{Ti}$, as manifested by a shift of some diffraction peaks of crystal planes of titanium toward smaller angles in comparison with pure microcrystalline titanium. After thermal treatment, no peaks associated with titanium hydride appeared. For all samples, the predominant phase is titanium. As regards the hydroxyapatite, the extreme heating conditions cause its decomposition and formation of apatite with different $\mathrm{Ca} / \mathrm{P}$ ratios. The presence of other phases is a common feature of TiHA composites. High temperature can cause degradation of structural stability of HA and contribute to its dehydration and decomposition (Ref 29). The stability of HA depend not only on temperature but also on the partial pressure of water in sintering atmosphere. With water present, hydroxyapatite can be formed and is a stable phase up to $1360{ }^{\circ} \mathrm{C}$, but without water the stable phases are tricalcium and tetracalcium phosphate (Ref 30). Moreover, the different initial titanium content resulted in different phase compositions in the Ti-HA composites which can influence their final properties (Ref 31, 32). Chenglin et al. suggested that the existence of Ti can only promote decomposition of $\mathrm{HA}$, but $\mathrm{HA}$ did not react with $\mathrm{Ti}$ (Ref 32).

The addition of blowing agent (in our work-titanium hydride) to Ti-HA powders has allowed the synthesis of porous Ti-HA nanocomposites. Change in $\mathrm{TiH}_{2}$ content influences the modification of amount of porosity, size of pores and their morphology. Apart from compaction pressure, the pore size of the sintered porous composites is determined by the size of the blowing agent. It is obvious that more porous structure is obtained by the higher addition of $\mathrm{TiH}_{2}$, while a less porous structure is obtained at a higher compaction pressure. Gu et al. reported that, besides compaction pressure, also sintering 


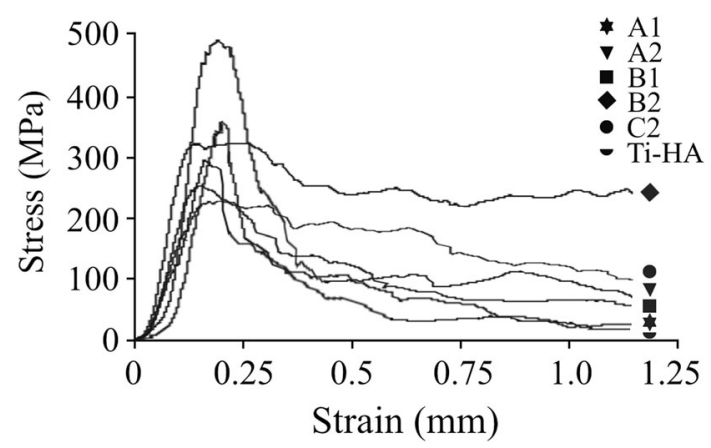

Fig. 13 Typical stress vs. strain response of the non-porous (Ti$\mathrm{HA})$ and porous (A1, A2, B1, B2, C2) nanocomposites (A-25\% $\mathrm{TiH}_{2}, \quad$ B-50\% $\quad \mathrm{TiH}_{2}, \quad \mathrm{C}-75 \% \quad \mathrm{TiH}_{2}, \quad 1$-compaction pressure $210 \mathrm{MPa}, 2$ - compaction pressure $415 \mathrm{MPa}$ )

Table 5 Mean values of corrosion current densities $\left(i_{\mathrm{C}}\right)$ and corrosion potentials $\left(E_{\mathrm{C}}\right)$ of studied porous Ti-HA nanocomposites measured in Ringer solution and Hanks' balanced salt solution (HBSS)

\begin{tabular}{llllll}
\hline & \multicolumn{2}{c}{ Ringer solution } & & \multicolumn{2}{c}{ HBSS } \\
\cline { 2 - 3 } \cline { 5 - 6 } Materials & $\boldsymbol{i}_{\mathbf{C}}, \mathbf{A} / \mathbf{c m}^{2}$ & $\boldsymbol{E}_{\mathbf{C}}, \mathbf{V}$ & & $\boldsymbol{i}_{\mathbf{C}}, \mathbf{A} / \mathbf{c m}^{2}$ & $\boldsymbol{E}_{\mathbf{C}}, \mathbf{V}$ \\
\hline $\mathrm{A} 1$ & $9.48 \cdot 10^{-7}$ & -1.26 & & $2.74 \cdot 10^{-6}$ & -1.16 \\
$\mathrm{~A} 2$ & $4.52 \cdot 10^{-7}$ & -0.66 & & $1.25 \cdot 10^{-6}$ & -1.10 \\
$\mathrm{~B} 1$ & $3.37 \cdot 10^{-6}$ & -0.81 & & $9.55 \cdot 10^{-5}$ & -1.29 \\
$\mathrm{~B} 2$ & $1.23 \cdot 10^{-6}$ & -0.95 & & $2.65 \cdot 10^{-5}$ & -1.04 \\
$\mathrm{C} 1$ & $5.45 \cdot 10^{-5}$ & -1.66 & & $\ldots$ & $\ldots$ \\
$\mathrm{C} 2$ & $1.41 \cdot 10^{-6}$ & -1.26 & $\ldots$ & $\ldots$ \\
\hline
\end{tabular}

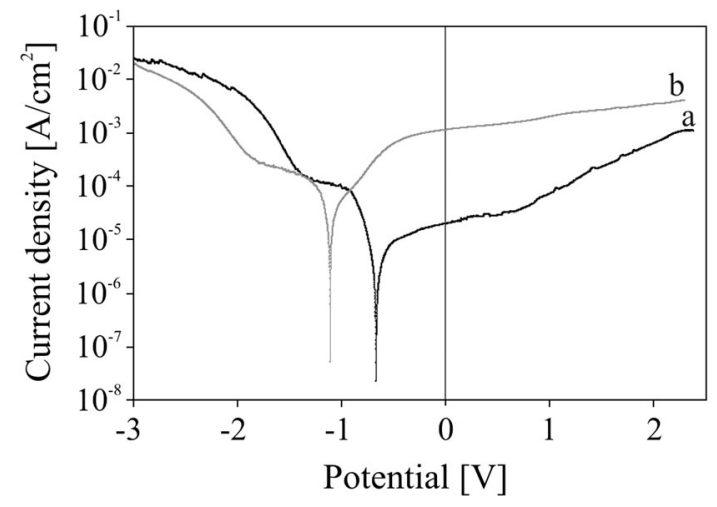

Fig. 14 Potentiodynamic polarization curves of porous Ti-20 wt.\% HA nanocomposite with $25 \% \mathrm{TiH}_{2}$ content measured (a) in Ringer solution and (b) in Hanks' balanced salt solution

temperature has influence on porosity and pore size of porous titanium alloys, and with an increase in the sintering temperature and compaction pressure, the porosity and pore size tend to decrease (Ref 23). Moreover, the authors found that the number of pores and the homogeneity of pore distribution increase with the addition of titanium hydride.

There are many materials that can be used as spacer material. For instance, apart titanium hydride (Ref 23), carbamide particles, ammonium hydrogen carbonate particles (Ref 24, 25), C-fibers, polyurethane foam or $\mathrm{H}_{2} \mathrm{O}_{2}$ (Ref 33) can

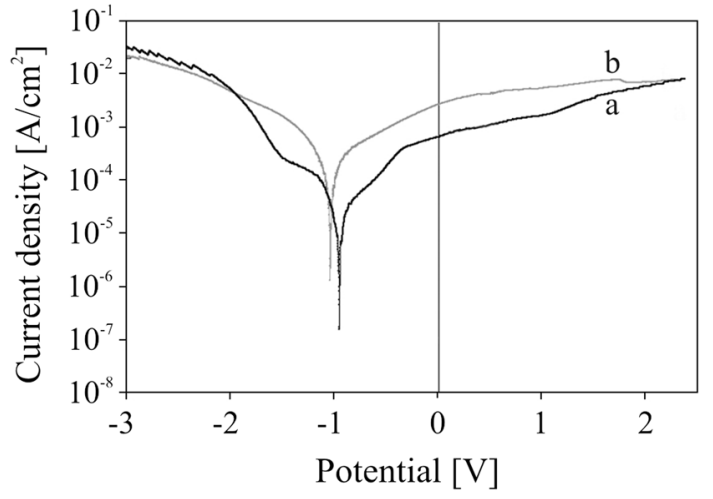

Fig. 15 Potentiodynamic polarization curves of porous Ti-20 wt.\% HA nanocomposite with $50 \% \mathrm{TiH}_{2}$ content measured (a) in Ringer solution and (b) in Hanks' balanced salt solution

be used as porogen. It is worth noting that unlike blowing materials, titanium hydride, during sintering, is decomposed into hydrogen and titanium. Hydrogen released by the decomposition of hydride introduces porosity to the material. In turn, titanium can participate in sintering.

So far, there have been many research on porous structure and bioactivity of biomaterials but has not been clearly defined the most favorable pore size for the most effective tissue growth. A pore size of $100 \mu \mathrm{m}$ is often cited as a minimum requirement for strong bonding of the tissue with implant. However, the researchers also reported that the microporous structure plays an important role in protein adsorption (Ref 34), proliferation (Ref 35), osteoinduction (Ref 20, 36) and distribution of bone within the ceramic scaffolds (Ref 37).

A number of reports have emphasized the formation of porous materials with wide gradient of porosity, and our present study showed the formation of porous nanocomposites mainly with macropore size and a negligible share of mesopores. Furthermore, small macropores with a size of $<5 \mu \mathrm{m}$ were observed.

In turn, Wang et al. sintered porous TiNbZr alloy using space holder particles of $500-800 \mu \mathrm{m}$ which gave pore size ranging from 300 to $800 \mu \mathrm{m}$. Besides large macropores, the authors observed some small macropores $(5-20 \mu \mathrm{m})$ which were present on the cell wall of porous alloys (Ref 25). Many reports suggest that one of very important factors for porous biomaterials is proper interconnectivity between pores because the connected pores will allow cells to grow inside the material and body fluid to circulate (Ref 26). Besides the pore interconnection size is critical in determining the quality of tissue ingrowth (Ref 9).

To achieve satisfactory implants, apart from porous structure and proper interconnection between pores, they should possess high strength and appropriate stiffness. The modulus of elasticity of bone and implant should be as similar as possible to avoid stress and to improve bone adaptation. Generally, the increase in porosity decreases the stiffness but on the other hand may cause reduction in strength. The properties of natural bones can change over a wide range depending on age and type of bones. For example, the compressive strength of bone ranges from 2 to $200 \mathrm{MPa}$, the Young's modulus ranges from 0.1 to $20 \mathrm{GPa}$, and the pore size and porosity of cancellous bone range from 20 to $1000 \mu \mathrm{m}$ and from 30 to $95 \%$, respectively (Ref 23,24$)$. Gu et al. produced porous Ti alloy with Young's 
modulus ranging from 5.8 to $9.5 \mathrm{GPa}$, porosity ranging from 43 to $59 \%$ and pore size of $90-190 \mu \mathrm{m}$ (Ref 23). In turn, Young's modulus of porous TiNbZr alloys changed from 21 to $1.6 \mathrm{GPa}$, while the porosity changed from 42 to $74 \%$ (Ref 25 ). The authors deduced that elastic modulus of the highly porous alloys is very sensitive to the homogeneity of strut thickness of the porous structure. Mechanical properties of porous Ti-HA nanocomposites studied in this work showed that despite high porosity they possess high compressive strength, which rise along with the reduction in porosity. From the medical applications point of view, the compressive strength of composites characterized by the best porosity and pore interconnectivity (samples B2 and C2) is still higher than the compressive strength of bone but lower than compressive strength of bulk titanium [450-965 MPa (Ref 38)]. Most probably, further rise of porosity will cause decreasing of compressive strength in order to match properties similar to properties of bones. For instance, Wen et al. produced porous titanium with the porosity $78 \%$ and compressive strength of $35 \mathrm{MPa}$ (Ref 24). The compressive strength of TiNbZr alloy with porosity of $69 \%$, produced by Wang et al., was $67 \mathrm{MPa}$ (Ref 25). The low content of porous agent results in a less porous and more durable composites. Therefore, controlling the share of porous agent and compaction pressure can impact on porosity and hence mechanical properties of composites.

Porous structure also influences the corrosion properties. More porous materials have a smaller resistance to electrochemical corrosion. The corrosion current densities summarized in Table 5 clearly decrease with increasing compaction pressure and decreasing amount of pore-forming agent. This trend is more evident for different parts of porous agent. 25 percent increase in the content of the porous factor causes a decrease in corrosion current densities by an order of magnitude. This could be due to the greater real surface areas obtained for high porous structures.

\section{Conclusion}

The porous titanium-20 wt.\% hydroxyapatite nanocomposites have been successfully prepared by mechanical alloying and powder metallurgical process. It is found that the Ti-HA nanocomposite sintering with various $\mathrm{TiH}_{2}$ contents (as the pore-forming agent) was an effective way to produce porous materials. After two-step heat treatment, the starting $\mathrm{TiH}_{2}$ phase was completely decomposed and only titanium and apatite phases were observed. The porous Ti-HA nanocomposites had a wide range of pores with size from few nanometers to 100 micrometers and porosity of $15.6-30.2 \% *(16.5-45.5 \% * *)$. An enhancement of the properties due to the nanoscale structures in consolidated materials was noticed. Despite the high porosity, Ti-HA nanocomposites have high values of compressive strength. Higher compaction pressure could be used to improve the corrosion resistance of the porous composites. However, increased compaction leads to the production of less porous structures and therefore their new bone ingrowths and transport of the body fluids. Based on the results obtained in this study, porous Ti-HA nanocomposites, produced by mechanical alloying and powder metallurgical process, have a high possibility for the application in the biomedical field of bone tissue engineering.

\section{Open Access}

This article is distributed under the terms of the Creative Commons Attribution 4.0 International License (http://creativeco mmons.org/licenses/by/4.0/), which permits unrestricted use, distribution, and reproduction in any medium, provided you give appropriate credit to the original author(s) and the source, provide a link to the Creative Commons license, and indicate if changes were made.

\section{References}

1. F. Takeshita, Y. Ayukawa, S. Iyama, K. Murai, and T. Suetsugu, LongTerm Evaluation of Bone-Titanium Interface in Rat Tibiae Using Light Microscopy, Transmission Electron Microscopy, and Image Processing, J. Biomed. Mater. Res., 1997, 37, p 235

2. M. Long and H.J. Rack, Review: Titanium Alloys in Total Joint Replacement-A Materials Science Perspective, Biomaterials, 1998, 19, p 1621

3. M.A. Khan, R.L. Williams, and D.F. Williams, Conjoint Corrosion and Wear in Titanium Alloys, Biomaterials, 1999, 20, p 765

4. H. Ramay and M. Zhang, Biphasic Calcium Phosphate Nanocomposite Porous Scaffolds for Load-Bearing Bone Tissue Engineering, Biomaterials, 2004, 25, p 5171

5. S.J. Hollister, R.D. Maddox, and J.M. Taboas, Optimal Design and Fabrication of Scaffolds to Mimic Tissue Properties and Satisfy Biological Constraints, Biomaterials, 2002, 23, p 4095

6. J.T. Clemow, A.M. Weinstein, J.J. Klawitter, J. Koeneman, and J. Anderson, Interface Mechanics of Porous Titanium Implants, $J$. Biomed. Mater. Res., 1981, 15, p 73

7. E. Tsuruga, H. Takita, H. Itoh, and Y. Koboki, Pore Size of Porous Hydroxyapatite as the Cell-Substratum Controls BMP-Induced Osteogenesis, J. Biochem., 1997, 121(2), p 317

8. A.I. Itälä, H.O. Ylänen, C. Ekholm, K.H. Karlsson, and H.T. Aro, Pore Diameter of More than $100 \mu \mathrm{m}$ is Not Requisite for Bone Ingrowth in Rabbits, J. Biomed. Mater. Res., 2001, 58, p 679

9. J.X. Lu, B. Flautre, K. Aselme, P. Hardouin, A. Gallur, B. Descamps, and B. Thierry, Role of Interconnections in Porous Bioceramics on Bone Recolonization In Vitro and In Vivo, J. Mater. Sci. Mater. Med., 1999, 10, p 111

10. K.A. Hing, Bioceramic Bone Graft Substitutes: Influence of Porosity and Chemistry, Int. J. Appl. Ceram. Technol., 2005, 2(3), p 184

11. K.A. Hing, B. Annaz, S. Saeed, P.A. Revell, and T. Buckland, Microporosity Enhances Bioactivity of Synthetic Bone Graft Substitutes, J. Mater. Sci. Mater. Med., 2005, 16, p 467

12. L.L. Hench, Bioceramics: From Concept to Clinic, J. Am. Ceram. Soc., 1991, 74, p 1487

13. H. Aoki, Science and Medical Applications of Hydroxyapatite, Takayama Press System Centre, JAAS, Tokyo, 1991

14. D.F. Williams, Review-Tissue-Biomaterials Interactions, J. Mater. Sci., 1987, 22, p 3421-3445

15. K. Niespodziana, K. Jurczyk, J. Jakubowicz, and M. Jurczyk, Fabrication and Properties of Titanium-Hydroxyapatite Nanocomposites, Mater. Chem. Phys., 2010, 123, p 160

16. K. Jurczyk, M.U. Jurczyk, K. Niespodziana, J. Jakubowicz, and M. Jurczyk, Titanium- $10 \mathrm{wt} \%$ 45S5 Bioglass Nanocomposite for Biomedical Applications, Mater. Chem. Phys., 2011, 131, p 540

17. M.U. Jurczyk, K. Jurczyk, K. Niespodziana, A. Miklaszewski, and M. Jurczyk, Titanium-SiO2 Nanocomposites and Their Scaffolds for Dental Applications, Mater. Charact., 2013, 77, p 99

18. F. Zeppelin, M. Hirscher, H. Stanzick, and J. Banhart, Desorption of Hydrogen from Blowing Agents Used for Foaming Metals, Compos. Sci. Technol., 2003, 63, p 2293

19. J.R. Woodard, A.J. Hilldore, S.K. Lan, C. Park, A.W. Morgan, J.A.C. Eurell et al., The Mechanical Properties and Osteoconductivity of Hydroxyapatite Bone Scaffolds with Multi-scale Porosity, Biomaterials, 2007, 28, p 45

20. P. Habibovic, T.M. Sees, M.A. van den Doel, C.A. van Blitterswijk, and K. de Groot, Osteoinduction by Biomaterials-Physicochemical and Structural Influences, J. Biomed. Mater. Res. A, 2006, 77A, p 747 
21. K. Anselme, Osteoblast Adhesion on Biomaterials, Biomaterials, 2000 21, p 667

22. A. Arifin, A.B. Sulong, N. Muhamad, J. Syarif, and M.I. Ramli, Material Processing of Hydroxyapatite and Titanium Alloy (HA/Ti) Composite as Implant Materials Using Powder Metallurgy: A Review, Mater. Des., 2014, 55, p 165

23. Y.W. Gu, M.S. Yong, B.Y. Tay, and C.S. Lim, Synthesis and Bioactivity of Porous Ti Alloy Prepared by Foaming with $\mathrm{TiH}_{2}$, Mater. Sci. Eng., C, 2009, 29, p 1515

24. C.E. Wen, M. Mabuchi, Y. Yamada, K. Shimojima, Y. Chino, and T. Asahina, Processing of Biocompatible Porous Ti and Mg, Scripta Mater, 2001, 45, p 1147

25. X. Wang, Y. Li, J. Xiomg, P.D. Hodgson, and C. Wen, Porous TiNbZr Alloy Scaffolds for Biomedical Applications, Acta Biomater, 2009, 5, p 3616

26. J.P. Li, J.R. de Wijn, C.A. van Blitterswijk, and K. de Groot, Porous Ti6A14 V Scaffold Directly Fabricating by Rapid Prototyping: Preparation and In Vitro Experiment, Biomaterials, 2006, 27, p 1223

27. M.A. Lopez-Heredia, J. Sohier, C. Gaillard, S. Quillard, M. Dorget, and P. Layrolle, Rapid Prototyped Porous Titanium Coated with Calcium Phosphate as a Scaffold for Bone Tissue Engineering, Biomaterials, 2008, 29, p 2608

28. C. Suryanarayana, Mechanical Alloying and Milling, Progr. Mat. Sci., 2001, 46, p 1

29. C. Chu, P. Lin, Y. Dong, X. Xue, J. Zhu, and Z. Yin, Fabrication and Characterization of Hydroxyapatite Reinforced with 20 vol\%Ti Particles for Use as Hard Tissue Replacement, J. Mater. Sci. Mater. Med., 2002, 13, p 985

30. B.D. Ratner, A.S. Hoffman, F.J. Schoen, and J.E. Lemons, Biomaterials Science: An Introduction to Materials in Medicine, Academic Press, Cambridge, 1996
31. C. Ning and Y. Zhou, Correlations Between the In Vitro and In Vivo Bioactivity of the Ti/HA Composites Fabricated by a Powder Metallurgy Method, Acta Biomater, 2008, 4, p 1944

32. C. Chenglin, Z. Jingchuan, Y. Zhongda, and W. Shidong, Hydroxyapatite-Ti Functionally Graded Biomaterial Fabricated by Powder Metallurgy, Mater. Sci. Eng., A, 1999, 271, p 95

33. E. Fidancevska, G. Ruseska, J. Bossert, Y.M. Lin, and A.R. Boccaccini, Fabrication and Characterization of Porous Bioceramic Composites Based on Hydroxyapatite and Titania, Mater. Chem. Phys., 2007, 103, p 95

34. X.D. Zhu, H.J. Zhang, H.S. Fan, W. Li, and X.D. Zhang, Effect of Phase Composition and Microstructure of Calcium Phosphate Ceramic Particles on Protein Adsorption, Acta Biomater, 2010, 6, p 1536

35. J. Wei, J. Jia, F. Wu, S. Wei, H. Zhou, H. Zhang, J.W. Shin, and Ch Liu, Hierarchically Microporous/Macroporous Scaffold of MagnesiumCalcium Phosphate for Bone Tissue Regeneration, Biomaterials, 2010, 31, p 1260

36. H.P. Yuan, K. Kurashina, J.D. de Bruijn, Y.B. Li, K. de Groot, and X.D. Zhang, A Preliminary Study on Osteoinduction of Two Kinds of Calcium Phosphate Ceramics, Biomaterials, 1999, 20(19), p 799

37. S.J. Polak, S.K. Lan Levengood, M.B. Wheeler, A.J. Maki, S.G. Clark, and A.J. Wagoner Johnson, Analysis of Roles of Microporosity and BMP-2 on Multiple Measures of Bone Regeneration and Healing in Calcium Phosphate Scaffolds, Acta Biomater, 2011, 7, p 1760

38. S.C.P. Cachinho and R.N. Correia, Titanium Scaffolds for Osteointegration: Mechanical, In Vitro and Corrosion Behaviour, J. Mater. Sci. Mater Med, 2008, 19, p 451

Publisher's Note Springer Nature remains neutral with regard to jurisdictional claims in published maps and institutional affiliations. 